\title{
Numerical simulations of coupled conduction-free convection in low conductive vertical finned surfaces
}

\author{
Alessandra De Angelis, Michele Libralato, Onorio Saro* \\ Università di Udine, DPIA, via delle Scienze 206, Udine 33100, Italy
}

Corresponding Author Email: onorio.saro@uniud.it

https://doi.org/10.18280/mmc_c.790306

Received: 24 March 2018

Accepted: 28 May 2018

\section{Keywords:}

free convection, finned surface, numerical simulation, low thermal conductivity

\begin{abstract}
Several industrial products and applications need to remove a large amount of thermal energy that arises from very small surfaces; typical solutions to this problem are heat sinks, dissipating heat devices in electrical and electronic appliances. In most cases they are cooled by means of finned surfaces and forced air. In some cases, especially in low-energy applications, free convection solutions could be preferable to forced convection ones. Usually, heat sinks are made of expensive aluminium or copper due to their high thermal conductivity. When the devices are small, and the solid-fluid temperature difference is limited, in free convection the heat transfer coefficient is typically low, and the thermal conductivity of the materials is less relevant. A less expensive possibility is the use of different materials that, despite their low thermal conductivity, can allow an easier production process as in the case of quasi-polymeric materials. In this paper, the free convection problem of small vertical finned surfaces immersed in still air has been investigated by means of numerical simulations in order to identify the influence of geometrical and physical parameters on the system performance with a moderately conductive polymeric material and a low-density $\mathrm{Zn}$-based alloy.
\end{abstract}

\section{INTRODUCTION}

Recent developments in electronic industry allowed the production of high performance devices with higher heat concentrations, this lead to increasing heat dissipation requests [1-3]. When high temperatures are avoided the device could reach a better performance level and higher durability.

Finned heat exchangers are one of the heat dissipation methods and they could be used as heat sinks with several applications in industry.

Finned surfaces are usually made of highly conductive materials such as aluminium or copper, to increase the heat exchange and obtain the highest performance using the minimum volume and surface. As seen below, their shape optimization has been studied in literature numerically, experimentally, analytically. Also, advanced applications with phase change materials have been investigated [3-4].

Heat sinks made of aluminium require costly processing techniques (for example die-casting) and, in low-cost electronic components could highly affect the cost of a product (this could be used for example on LED lamps). Many geometry conformations and design procedures have been proposed in literature [5-7] to reduce the amount of material used. Also, substituting the aluminium with other, less conductive, materials could lead to general cost reductions when less efficient heat sinks are required, and less expensive processing techniques could be used.

This study presents the numerical evaluation of the efficiency of heat sinks made of low-conductivity materials (PPS, steel) compared to the efficiency of heat sinks of highly conductive materials (Aluminium and Zn-alloy) in natural convection applications with low convective heat transfer coefficients.

To identify a correlation for Nusselt number, an experimental investigation about the natural convection in vertical finned plates, has been proposed by Elenbaas [8], that found an increase in heat removed with the increase of the fin spacing. Later, Starner and McManus [9] evaluated experimentally the influence of the heated base plate at the bottom of parallel plates on the performance of the heat sink. Other experiments [10] have been carried out to identify the value of the ratio between the fin height and the spacing that maximizes the heat transfer. Interesting results have been found in an experimental investigation by Jones and Smith [11], that proposed a correlation for Nusselt number which considers the fin spacing.

In the present paper, the free convection problem of small vertical finned surfaces immersed in still air has been investigated by means of numerical simulations in order to identify the influence of geometrical and physical parameters on the system performance with a moderately conductive polymeric material and a low-density Zn-based alloy.

In free convection the heat transfer coefficient is typically low, and the thermal conductivity of the materials is less relevant.

The interest of investigating the behaviour of low-cost moderately conductive materials arises from the consideration that the fin efficiency depends on the parameter $m$ defined as:

$\mathrm{m}=\sqrt{\frac{\mathrm{h} \cdot \mathrm{P}}{\mathrm{k} \cdot \mathrm{A}}}$

Where $\mathrm{h}$ is the thermal convective coefficient, $\mathrm{P}$ is the perimeter of the fin, $\mathrm{k}$ is the fin thermal conductivity and $\mathrm{A}$ is 
the cross-sectional area of the fin.

In equation (1) the convective coefficient $h$ and the fin thermal conductivity k play an opposite role. Thus, a low heat transfer coefficient, typical for low temperature differences in free convection, coupled with low thermal conductivity does not negatively affect the efficiency of the fins' system.

\section{SIMULATIONS}

\subsection{Computational domain}

The geometry of the heat sink with rectangular fins is shown in Figure 1 and the dimensions are summarized in Table 1.

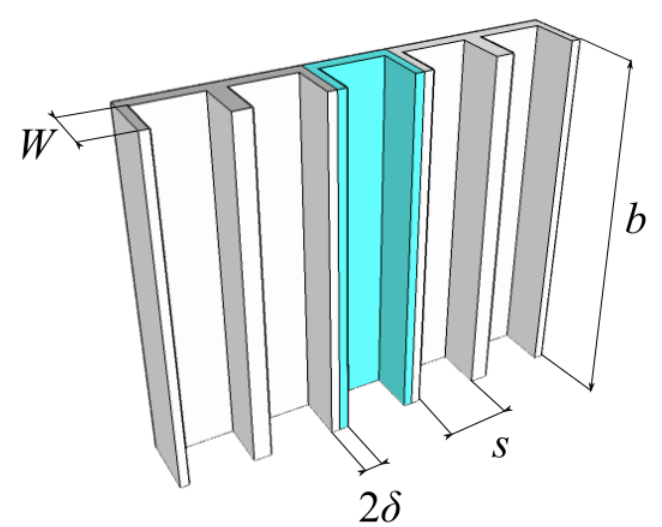

Figure 1. Geometry of the whole heat sink. The simulated module is highlighted in blue

Table 1. Geometric parameters of the rectangular fin heat sinks used in the simulations

\begin{tabular}{cc}
\hline Fin dimensions & Value (mm) \\
\hline Length - W $(\mathrm{mm})$ & 50 \\
\hline Spacing - s $(\mathrm{mm})$ & 20 \\
\hline Thickness $-2 \delta(\mathrm{mm})$ & $1-2-2.5-3-3.5-4-5-6-8-10-$ \\
& $12-14-16-18-20-22$ \\
\hline Height - b $(\mathrm{mm})$ & 100 \\
\hline
\end{tabular}

Symmetry conditions has been employed defining the computational domain and only a module of heat sink has been considered, as highlighted in Figure 1.

Different material has been considered for the heat sink: PPS, Zn-alloy, steel and aluminium; the thermo-physical properties of materials are listed in Table 2

Table 2. Physical properties of materials

\begin{tabular}{cclc}
\hline Material & $\boldsymbol{\rho}\left(\mathbf{k g} / \mathbf{m}^{\mathbf{3}}\right)$ & $\mathbf{c}_{\mathbf{p}}(\mathbf{J} / \mathbf{k g})$ & $\mathbf{k}(\mathbf{W} / \mathbf{m} \cdot \mathbf{K})$ \\
\hline PPS & 1700 & 900 & 20 \\
\hline Steel & 8030 & 502 & 16 \\
\hline Zn-alloy & 6300 & 435 & 100 \\
\hline Aluminium & 2719 & 871 & 202 \\
\hline
\end{tabular}

\subsection{Governing equations}

The numerical simulation was conducted using the commercial CFD code, Fluent 6.3.

Assumptions for the numerical analysis are the following:
(1) the flow field is three-dimensional, steady, laminar and incompressible invoking Boussinesq approximation for buoyancy force;

(2) air is treated as an ideal gas with constant thermophysical properties except for the density;

(3) radiation heat transfer is negligible.

The considered equations of conservation of mass, momentum and the energy are the following:

Continuity equation:

$\frac{\partial \mathrm{u}}{\partial \mathrm{x}}+\frac{\partial \mathrm{v}}{\partial \mathrm{y}}+\frac{\partial \mathrm{w}}{\partial \mathrm{z}}=0$

$\mathrm{X}$ - momentum equation

$\rho\left(\mathrm{u} \frac{\partial \mathrm{u}}{\partial \mathrm{x}}+\mathrm{v} \frac{\partial \mathrm{u}}{\partial \mathrm{y}}+\mathrm{w} \frac{\partial \mathrm{u}}{\partial \mathrm{z}}\right)=-\frac{\partial \mathrm{p}}{\partial \mathrm{x}}+\mu\left(\frac{\partial^{2} \mathrm{u}}{\partial \mathrm{x}^{2}}+\frac{\partial^{2} \mathrm{u}}{\partial \mathrm{y}^{2}}+\frac{\partial^{2} \mathrm{u}}{\partial \mathrm{z}^{2}}\right)$

$\mathrm{Y}$ - momentum equation

$\rho\left(\mathrm{u} \frac{\partial \mathrm{v}}{\partial \mathrm{x}}+\mathrm{v} \frac{\partial \mathrm{v}}{\partial \mathrm{y}}+\mathrm{w} \frac{\partial \mathrm{v}}{\partial \mathrm{z}}\right)=-\frac{\partial \mathrm{p}}{\partial \mathrm{y}}+\mu\left(\frac{\partial^{2} \mathrm{v}}{\partial \mathrm{x}^{2}}+\frac{\partial^{2} \mathrm{v}}{\partial \mathrm{y}^{2}}+\frac{\partial^{2} \mathrm{v}}{\partial \mathrm{z}^{2}}\right)-\rho \mathrm{g}$

Z - momentum equation:

$\rho\left(\mathrm{u} \frac{\partial \mathrm{w}}{\partial \mathrm{x}}+\mathrm{v} \frac{\partial \mathrm{w}}{\partial \mathrm{y}}+\mathrm{w} \frac{\partial \mathrm{w}}{\partial \mathrm{z}}\right)=-\frac{\partial \mathrm{p}}{\partial \mathrm{z}}+\mu\left(\frac{\partial^{2} \mathrm{w}}{\partial \mathrm{x}^{2}}+\frac{\partial^{2} \mathrm{w}}{\partial \mathrm{y}^{2}}+\frac{\partial^{2} \mathrm{w}}{\partial \mathrm{z}^{2}}\right)$

energy equation:

$\mathrm{u} \frac{\partial\left(\rho c_{\mathrm{p}} \mathrm{T}\right)}{\partial \mathrm{x}}+\mathrm{v} \frac{\partial\left(\rho \mathrm{c}_{\mathrm{p}} \mathrm{T}\right)}{\partial \mathrm{y}}+\mathrm{w} \frac{\partial\left(\rho \mathrm{c}_{\mathrm{p}} \mathrm{T}\right)}{\partial \mathrm{z}}=\mathrm{k}\left(\frac{\partial^{2} \mathrm{~T}}{\partial \mathrm{x}^{2}}+\frac{\partial^{2} \mathrm{~T}}{\partial \mathrm{y}^{2}}+\frac{\partial^{2} \mathrm{~T}}{\partial \mathrm{z}^{2}}\right)$

\subsection{Numerical method}

The finite volume approach is adopted to solve the abovementioned equation. The convective terms are discretized using the power-law scheme, whereas for diffusive terms the central difference is employed. The SIMPLE pressurevelocity coupling is adopted in the pressure-based solver. Referring to spatial discretization method, a body-forceweighted method for the pressure equation and second order upwind for momentum and energy equations are set.

In order to reduce the influence of open-boundary conditions the computational domain has been extended vertically half time the fin height above and below the heat sink and horizontally to a distance equal to fin length in front of the finned surface (Figure 2).

A grid independence analysis was carried out by varying the number of grid points, choosing a mesh of about 750000 cells.

\subsection{Boundary conditions}

Two planes of symmetry are imposed (pink coloured in Figure 2) parallel to the $x-z$ plane; open boundary conditions (magenta coloured in Figure 2) are set as pressure inlets with $1 \mathrm{~atm}$. The rear side of the heat sink (green coloured in Figure 2 ) is the interface with the component, which needs to be cooled; on this surface a constant temperature $\mathrm{T}_{\mathrm{s}}=65^{\circ} \mathrm{C}$ is imposed. The ambient air temperature $\mathrm{T}_{\infty}$ is set to $27^{\circ} \mathrm{C}$ and the thermophysical properties are evaluated at a reference temperature defined as

$\mathrm{T}_{\mathrm{f}}=\frac{\mathrm{T}_{\mathrm{s}}+\mathrm{T}_{\infty}}{2}$ 
The reference temperature (6) is defined as a modified film temperature, where the heat-sink temperature is used instead of the fin base temperature.

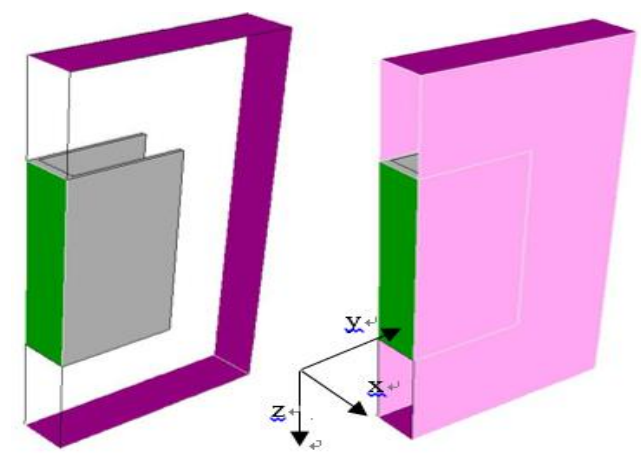

Figure 2. Isometric view of the heat sink with the boundary conditions

\section{SIMULATIONS}

\subsection{Identification of optimal fin spacing}

A key parameter to design the fin spacing is the Rayleigh number Ra, since it affects the development of thermal layers in natural convection. In particular, to identify an optimal dimension of the fin spacing $\mathrm{s}_{\mathrm{opt}}$, the correlation proposed by Bar-Cohen and Rohsenow [12] for symmetric isothermal plates is used:

$\mathrm{S}_{\mathrm{opt}}=2.714\left(\frac{\mathrm{Ra}_{\mathrm{s}}}{\mathrm{s}^{3} \mathrm{~b}}\right)^{-0.25}$

with:

$\mathrm{Ra}_{\mathrm{s}}=\frac{\mathrm{g} \beta\left(\mathrm{T}_{\mathrm{s}}-\mathrm{T}_{\infty}\right) \mathrm{s}^{3}}{\mathrm{a} v}$

resulting:

$\mathrm{s} \cong 0.02 \mathrm{~m}$

\subsection{Model validation}

In literature, several correlations have been developed that predict the natural convective heat exchange of a vertical flat plate. Therefore, to validate the numerical model, a comparison between the simulation results and some correlations has been carried out.

Churchill [13] identifies a correlation and finds that equations closely fit several experimental data [14-16]. The Churchill correlations are the following:

$\mathrm{Nu}=\left[\left(\mathrm{Nu}_{\mathrm{l}}\right)^{\mathrm{m}}+\left(\mathrm{Nu}_{\mathrm{t}}\right)^{\mathrm{m}}\right]^{1 / \mathrm{m}}$ with $\mathrm{m}=6$

where

$\mathrm{Nu}_{\mathrm{t}}=\mathrm{C}_{\mathrm{t}}^{\mathrm{V}} \mathrm{Ra}^{1 / 3} /\left(1+1.4 \cdot 10^{9} \mathrm{Pr} / \mathrm{Ra}\right)$

$\mathrm{Nu}_{\mathrm{l}}=\frac{2}{\ln \left(1+2 / \mathrm{Nu}^{\mathrm{T}}\right)}$

with $\mathrm{Nu}^{\mathrm{T}}=\overline{\mathrm{C}}_{\mathrm{l}} \mathrm{Ra}^{1 / 4} ; \mathrm{C}_{\mathrm{t}}^{\mathrm{V}}=0.103$ and $\overline{\mathrm{C}}_{\mathrm{l}}=0.51$.
Comparing the heat transfer coefficient obtained from numerical simulation with the one evaluated by means of the correlation (11), a percentage error equal to $1.4 \%$ has been found.

\subsection{Simulation results}

Simulation results allow to know the velocity and the temperature distribution and therefore to evaluate the natural convection heat transfer coefficient.

In Figure 3 the temperature distribution on a horizontal plane placed in the middle of the domain can be seen.
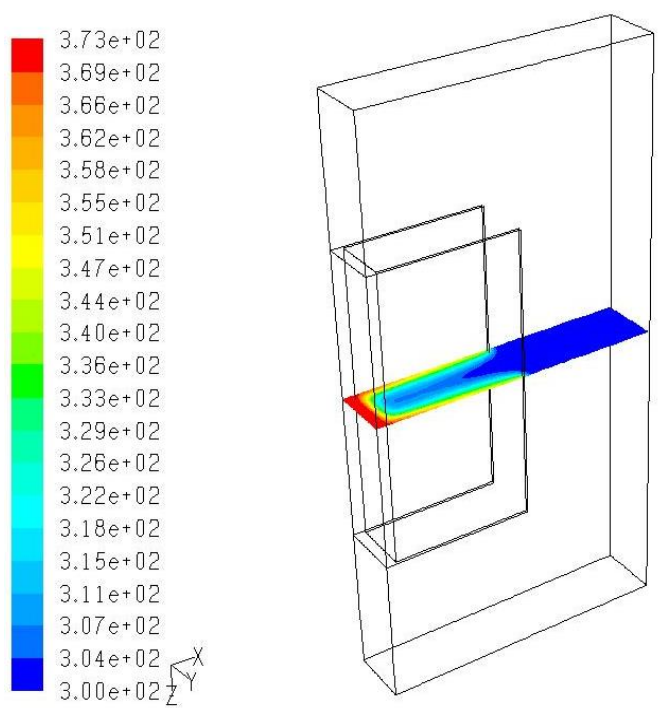

Figure 3. Temperature field $[\mathrm{K}]$ for a $1 \mathrm{~mm}$ thick aluminium fin in a horizontal plane on the middle of the heat sink

In Figure 4 the temperature distribution on a vertical plane is shown. The colour map result is highly influenced by the displacement of the air, due to free convection
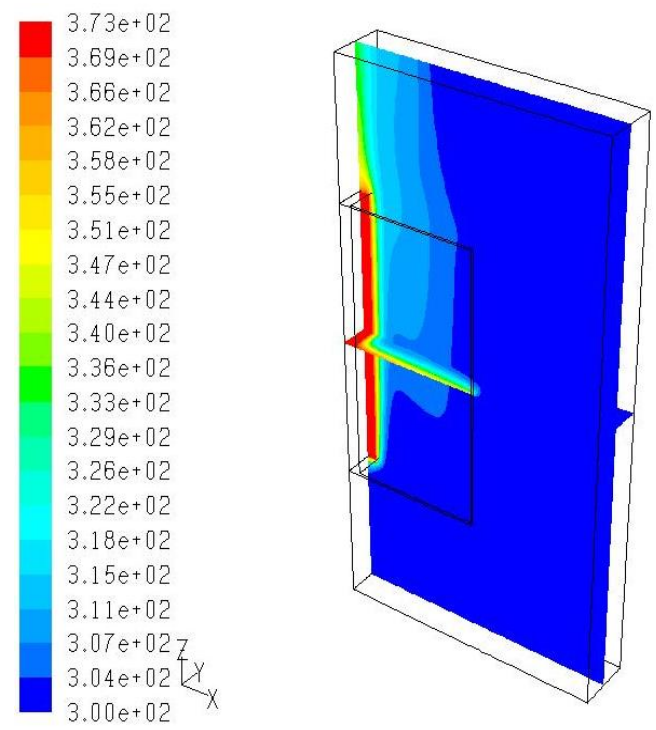

Figure 4. Temperature field $[\mathrm{K}]$ for a $1 \mathrm{~mm}$ thick aluminium fin in a vertical plane on the middle of the heat sink

The motion of the fluid, arising from the fins' base, due to the variation of the density of air is shown in Figure 5 by the contours of the air velocity at different horizontal planes. 

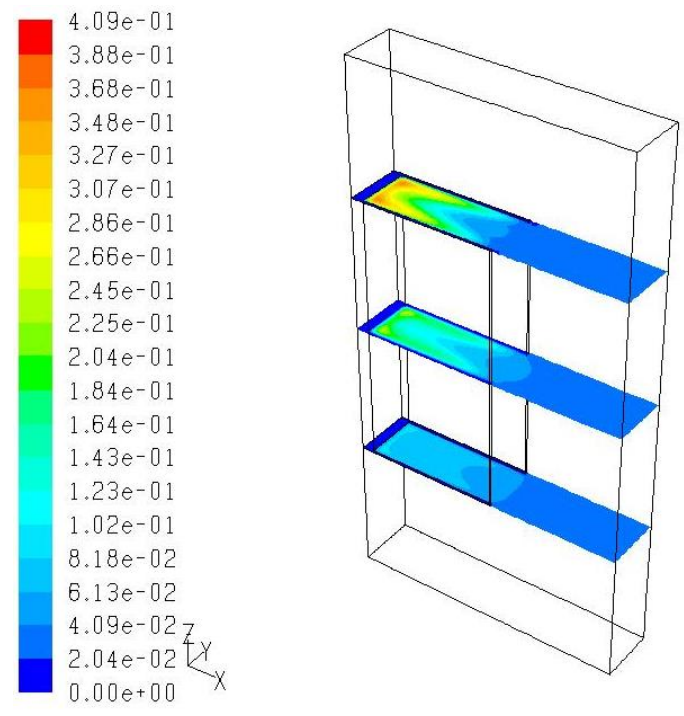

Figure 5. Air velocity contours $[\mathrm{m} / \mathrm{s}]$ on three horizontal planes

A non-dimensional parameter $\tilde{\delta}$ has been defined as ratio between the fin thickness $\delta$ and the fin spacing s; different simulations have been carried out by varying the parameter $\tilde{\delta}$ from 0.05 to 1 , with steps of 0.05 .

As the parameter $\tilde{\delta}$ increases, the total number of fins on the heat sink decreases, therefore the total convection heat transfer rate has been considered to identify an optimal fin thickness. Results of simulations (in Figure 6) show that the specific convection rate increases with larger fin spacings and reaches a maximum, after which the value of heat transfer decreases.

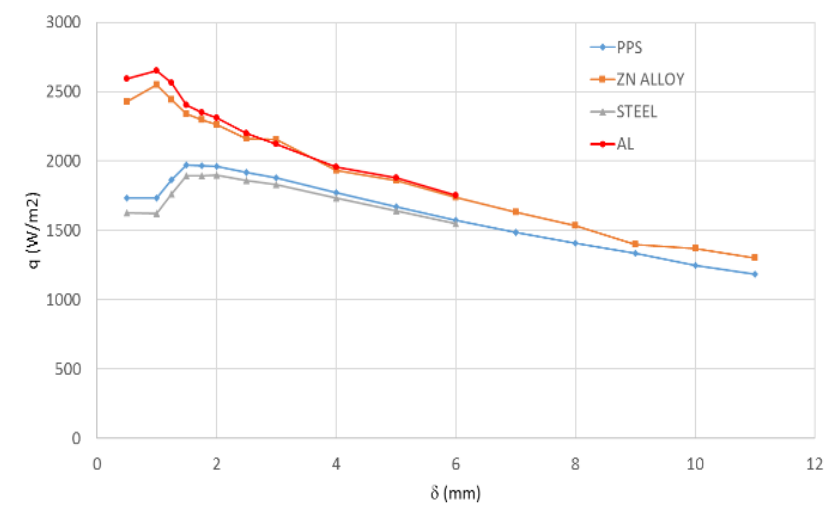

Figure 6. Trend of the removed heat flux depending on the thickness of fins for different materials

In Figure 6 clearly appears that the value of optimal fin thickness depends on the thermal characteristics of material.

For fins made of PPS or steel, which have a lower value of thermal conductivity, the value of $\tilde{\delta}$ that maximizes the amount of removed heat flux is 0.10 , with a corresponding fin thickness of $2 \mathrm{~mm}$.

For $\mathrm{Zn}$-alloy and aluminium made fins the maximum value of the heat flux occurs for $\tilde{\delta}=0.15$ which corresponds with a fin thickness of $3 \mathrm{~mm}$.

From the simulation results appears that, the average heat transfer coefficient of finned equipment has a lower value than the one of the flat plate; the removed heat flux is chosen as parameter to evaluate the advantage of using a finned heat sink.
Figure 7 shows the ratio between the heat flux removed by a vertical fin array and that removed by a vertical flat plate with the same height and width. The heat transfer performance increases with the thermal conductivity of the material.

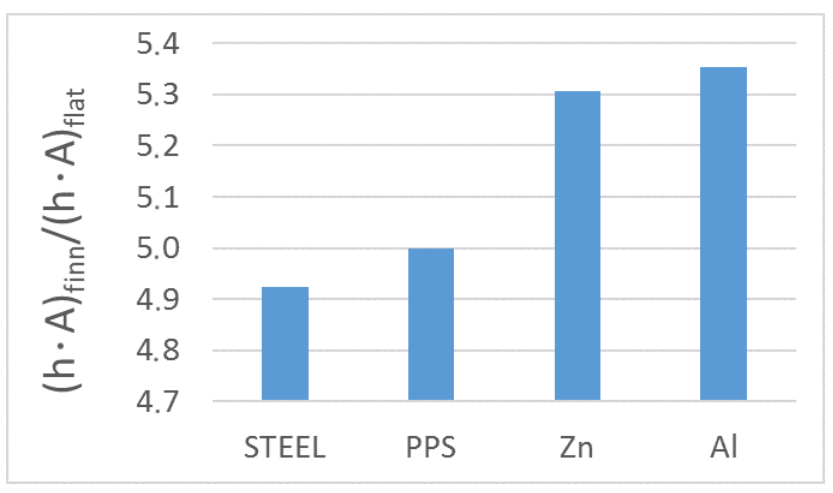

Figure 7. Ratio between the heat flux removed by a vertical fin array and the one removed by a vertical flat plate for different materials

From the comparison it can be noted that the steel made finned surface can be efficiently substituted by the PPS made one and, with a small efficiency loss, the aluminium fins can be substituted by Zn-alloy fins. Both substitutions lead to a significant reduction in the production costs especially due to lower melting temperatures.

Investigating on the dependency of this ratio on the conducive resistance of the fin, a linear correlation has been found (Figure 8).

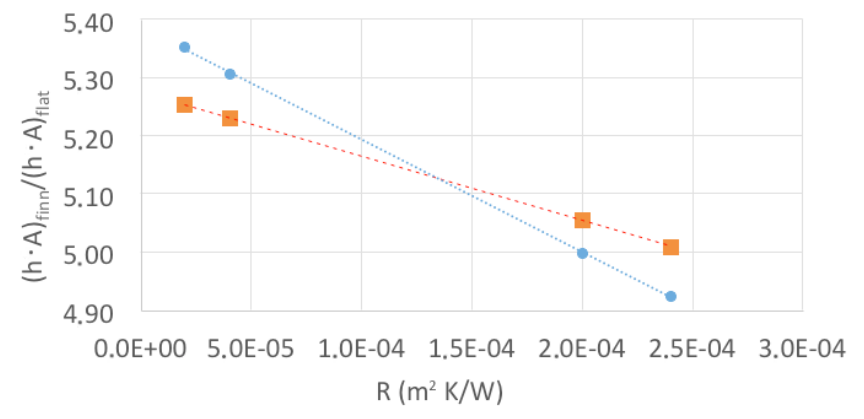

Figure 8. Linear trend of the ratio between the heat flux removed by a vertical fin array and the one removed by a vertical flat plate depending on the conductive resistance of the fin defined as $\mathrm{R}=\delta / \mathrm{k}$

Results shown in Figure 8 concern two fin geometries; it would be advisable to extend the analysis to different cases varying geometrical parameters.

\section{CONCLUSIONS}

Conduction coupled to free convection of vertical finned surfaces has been numerically simulated with a commercial CFD code. Heat sinks made with materials with different thermal conductivities have been compared to evaluate the efficiency of low-conductive solutions. In each case the optimum fin thickness has been found for an assigned cooling surface and fin length to have the same occupied gross volume. 
For the heat sinks of low-conductive materials, thicker fins are necessary to reach the maximum of the removed heat flux. Moreover, it has been observed that the maximum removed heat flux is decreasing with the decrease of the conductivity of the material. Among the significant results, a linear correlation has been found between the heat flux increase given by the addition of the fins to the cooled surface and a characteristic parameter of the fins' dimension and material.

In conclusion, it has been found that alternative low-cost materials are suitable to substitute the commonly used ones in finned surfaces production. The thermal efficiency loss is reasonable in the case of aluminium and $\mathrm{Zn}$-alloy, while PPS has been found to perform better than steel.

\section{REFERENCES}

[1] Ahmed HE, Salman BH, Kherbeet AS, Ahmed MI. (2018). Optimization of thermal design of heat sinks: A review. International Journal of Heat and Mass Transfer 118: $129-153$. https://doi.org/10.1016/j.ijheatmasstransfer.2017.10.099

[2] Garimella SV, Fleischer AS, Murthy JY, Keshavarzi A, Prasher R, Patel C, Raad PE. (2008). Thermal challenges in next-generation electronic systems. IEEE Transactions on Components and Packaging Technologies 31(4): 801815. https://doi.org/10.1109/TCAPT.2008.2001197

[3] Sakanova A, Tseng KJ. (2018). Comparison of pin-fin and finned shape heat sink for power electronics in future aircraft. Applied Thermal Engineering 136: 364-374. https://doi.org/10.1016/J.Applthermaleng.2018.03.020

[4] Muhammad AH, Giovannelli A, Irfan M, Bin IT. (2018). Thermal management of electronics: An experimental analysis of triangular, rectangular and circular pin-fin heat sinks for various PCMs. International Journal of Heat and Mass Transfer 123: 272-284.

[5] Haghighi SS, Goshayeshi HR, Safaei MR. (2018). Natural convection heat transfer enhancement in new designs of plate-fin based heat sinks. International Journal of Heat and Mass Transfer 125: 640-647. https://doi.org/10.1016/J.ijheatmasstransfer.2018.04.122
[6] Effendi NS, Kim KJ. (2017). Orientation effects on natural convective performance of hybrid fin heat sinks. Applied Thermal Engineering 123: 527-536. https://doi.org/10.1016/J.Applthermaleng.2017.05.134

[7] Feng S, Shi M, Yan H, Sun S, Li F, Lu TJ. (2018). Natural convection in a cross-fin heat sink. Applied Thermal Engineering 132: 30-37. https://doi.org/10.1016/J.applthermaleng.2017.12.049

[8] Elenbaas W. (1942). Heat dissipation of parallel plates by free convection. Physica 9(1): 1-28. https://doi.org/10.1016/S0031-8914(42)90053-3

[9] Starner KE, McManus HN. (1963). An experimental investigation of free-convection heat transfer from rectangular-fin arrays. Journal of Heat Transfer 85(3): 273. https://doi.org/10.1115/1.3686097

[10] Welling JR, Wooldridge CB. (1965). Free convection heat transfer coefficients from rectangular vertical fins. Journal of Heat Transfer 87(4): 439. https://doi.org/10.1115/1.3689135

[11] Jones CD, Smith LF. (1970). Optimum arrangement of rectangular fins on horizontal surfaces for freeconvection heat transfer. Journal of Heat Transfer 92: 6$10 \mathrm{https}: / / \mathrm{dx}$.doi.org/10.1115/1.3449648

[12] Bar-Cohen A, Rohsenow WM. (1984). Thermally optimum spacing of vertical, natural convection cooled, parallel plates. Journal of Heat Transfer 106: 116. https://dx.doi.org/10.1115/1.3246622

[13] Churchill SW. (1983). Free convection around immersed bodies in heat exchanger design handbook E. U. Schltinder. editor-in-chief, Hemisphere Publishing, New York.

[14] Saunders OA. (1936). The effect of pressure on natural convection in air. Proc. Royal Soc., Ser. A (157): 278291. http://dx.doi.org/10.1098/rspa.1936.0194

[15] Pirovano A, Viannay S, Jannot M. (1970). Convection Naturelie en Regime Turbulent le Long d'une Plaque Plane Verticale, Rep. EUR 4489f. Commission of the European Communities.

[16] Clausing AM, Kempka SN. (1981). The influences of property variations on natural convection from vertical surfaces. J. Heat Transfer. 103(609). https://dx.doi.org/10.1115/1.3244515 